\title{
Completeness of bladder cancer staging in the Danish Cancer Registry, 2004-2009
}

This article was published in the following Dove Press journal:

Clinical Epidemiology

16 August 2012

Number of times this article has been viewed

\section{Louise Holland-Bill' \\ Trine Frøslev' \\ Søren Friis ${ }^{2}$ \\ Morten Olsen' \\ Niels Harving ${ }^{3}$ \\ Michael Borre ${ }^{4}$ \\ Mette Søgaard ${ }^{1,5}$}

'Department of Clinical Epidemiology, Aarhus University Hospital, Aarhus,

2Danish Cancer Society Research Center, Danish Cancer Society,

Copenhagen, ${ }^{3}$ Department of Clinical Medicine, Department of Urology, Aalborg University Hospital, Aalborg, ${ }^{4}$ Department of Clinical Medicine, Department of Urology, Aarhus University Hospital, Aarhus, ${ }^{5}$ Department of Clinical Microbiology, Aalborg Hospital, Aarhus University Hospital, Denmark
Correspondence: Louise Holland-Bill Department of Clinical Epidemiology, Aarhus University Hospital, Olof Palmes Álle 43-45, 8200 Aarhus N, Denmark Tel +45 87। 68254

Fax +45 87I 672I5

Email louise.bill@dce.au.dk
Objective: To investigate the completeness of tumor, node, and metastasis (TNM) staging for invasive bladder cancer in the Danish Cancer Registry (DCR).

Methods: From the DCR, we retrieved data on TNM stage, year of diagnosis, sex, and age of all-incident invasive bladder cancer patients between 2004 and 2009. Data on comorbidity was obtained from the Danish National Patient Register. We estimated the completeness of TNM registration in the DCR overall and stratified the analysis by sex, age, year of cancer diagnosis, and Charlson comorbidity score. Through knowledge of pathophysiology and clinical coding practice, we designed a clinically based algorithm that allowed tumors with certain missing TNM-stage components to be placed in localized, regional, distant, and unknown categories.

Results: The overall completeness of TNM staging for bladder cancer was $44.1 \%$ (95\% confidence interval [CI]: 42.7-45.5). Completeness decreased from $60.9 \%$ (95\% CI: 40.6-78.6) in patients aged $0-39$ years to $25.5 \%$ (95\% CI: $23.2-27.9)$ in patients aged 80 years or older. Among patients with a low level of comorbidity, completeness was $48.4 \%$ (95\% CI: 46.6-50.3), decreasing to $34.0 \%$ (95\% CI: 30.4-37.8) among those with a high level of comorbidity. The highest proportion of missing TNM data was found for registration of lymph node metastases. Defining T1 cancer as completely registered, regardless of missing N and M stage, increased TNM-registration completeness to $61.8 \%$. When we applied a clinically based algorithm, only $29.6 \%$ of tumors had an unknown stage.

Conclusion: The overall completeness of TNM staging for bladder cancer in the DCR was low, especially with increasing age and high level of comorbidity. Thus, restricting analyses to bladder cancer patients with complete data on stage may produce substantially selected study populations. Careful considerations should thus be made on handling missing data.

Keywords: bladder cancer, TNM stage, completeness, cancer registry, Denmark

\section{Introduction}

Bladder cancer is the fourth most prevalent cancer among men and the fifteenth most prevalent cancer among women in developed countries, with 382,660 new cases and 150,282 deaths worldwide in 2008..$^{1,2}$ In Denmark, the standardized incidence rate of bladder cancer (including noninvasive precancerous lesions) is 46/100,000 among men and 14/100,000 among women, accounting for 4\%-5\% of all cancers. The incidence has been fairly stable over the last decade. ${ }^{3}$

Information on cancer stage in Danish hospitals and cancer registries is recorded according to The American Joint Committee on Cancer's Tumor, Node and Metastasis (TNM) classification (AJCC-TNM). ${ }^{4}$ A given TNM class reflects the severity and spread of cancer at the time of diagnosis. "T" describes the local extent of the tumor, 
"N" denotes the presence of lymph node metastases, and "M" the presence of distant metastases. TNM staging is essential for the choice of treatment of most cancers and constitutes an important prognostic predictor. ${ }^{5}$

In 2000 and 2005, the Danish Government issued the National Cancer Action Plans, which encompass initiatives to enhance the diagnosis and treatment of cancer to improve cancer survival in general. ${ }^{6}$ As part of these initiatives, it was decided that the Danish Cancer Registry (DCR) should be used as a tool for national health care planning, for monitoring the effect of new initiatives and to facilitate cancer research. The TNM staging of incident cancers has been reported to the DCR since 2004. ${ }^{7}$ Although the DCR constitutes an important data resource in health care monitoring, as well as in clinical and epidemiological research, the completeness of TNM staging has not yet been evaluated. Missing data on TNM stage in the DCR may bias study results if the missing data are not distributed randomly. Therefore, we conducted this study to evaluate the completeness of TNM classification in patients with invasive bladder cancer. To improve our understanding of how the missing data may potentially bias study results, we stratified the results of completeness by sex, calendar period, patient age, and level of comorbidity.

\section{Materials and methods}

We performed this study in Denmark, which has a population of about 5.5 million. All residents in Denmark are provided with free, tax-supported medical care. Since 1968, the Danish Civil Registration System has assigned a unique ten-digit personal identification number (CPR-number), encoding date of birth and gender, to all Danish residents. ${ }^{8}$ This number is used in all Danish registries, allowing unambiguous individuallevel data linkage.

\section{Ascertainment of patients with bladder cancer}

From the DCR, we identified all patients with a primary diagnosis of invasive bladder cancer (according to the International Classification of Disease, 10th revision [ICD-10] code C67) between January 1, 2004 and December 31, 2009. Invasive tumors are defined as tumors that have invaded into or beyond the lamina propria of the bladder. Premalignant tumors (Ta and Tis) are not registered under the ICD-10 code C67. From the DCR, we obtained information on date of diagnosis, age, gender, histologic verification of tumor (based on morphology codes in the DCR), and TNM stage. Through knowledge of pathophysiology and clinical coding practice, we designed a clinically based algorithm that allowed for categorization of tumors with certain missing TNM stage components into localized, regional, distant, and unknown stage (see Appendix). A registration of Tx, Nx, and/or Mx (denoting that information on tumor size, lymph node metastasis, or distant metastases were not available or could not be assessed) was allowed if the available data on T, N, or M provided sufficient and clinical meaningful information to allocate the cancer case to one of the three defined tumor categories. The unknown tumor category included primarily locally advanced tumors (T3 or T4) with unknown $\mathrm{N}$ and/or $\mathrm{M}$ stage.

The DCR has recorded information on incident cancers in the Danish population since 1943. ${ }^{7,9}$ Information contains personal characteristics, including CPR-number, age at diagnosis, date of death or migration, and tumor characteristics, including cancer diagnosis, topography, and morphology (according to the International Classification of Diseases for Oncology [ICD-O]), laterality, stage, and date of diagnosis. Cancer diagnoses have been registered according to, or converted from ICD-O to ICD-10 since 1978. As mentioned, stage has been recorded using the TNM classification since 2004. ${ }^{4,7}$ To prevent double-registration, the DCR does not accept multiple tumors of the same morphology. In general, only invasive neoplasias are regarded as cancer cases in the DCR. However, this does not apply to urinary tract tumors, including bladder tumors, for which precancerous or precursor lesions (ICD-10 codes: D090, D303, and D414) are regarded as a cancer case..$^{10}$

\section{Comorbidity data}

Data on comorbidity were obtained from the Danish National Patient Registry. ${ }^{11}$ The registry contains data on all admissions to nonpsychiatric hospitals in Denmark since 1977 and outpatient visits since 1995 and information includes the CPRnumber, date of admission or contact, date of discharge, and diagnosis codes. We described preexisting comorbidity using a modified version of the Charlson comorbidity index (CCI), in which each disease category has an associated weight, based on the adjusted risk of 1-year mortality. ${ }^{12,13}$ We generated CCI scores from hospital diagnoses (excluding bladder cancer) within 10 years preceding the date of cancer diagnosis. We computed the following CCI scores: 0 (low), 1-2 (medium), and 3+ (high).

\section{Statistical analysis}

We calculated the proportion of complete TNM stage registrations and corresponding 95\% confidence intervals (CI), overall, and by each stage category (ie, T, N, and M). 
A registration of $\mathrm{Tx}, \mathrm{Nx}$ or $\mathrm{Mx}$ was defined as unknown stage. We stratified completeness by gender, age ( $0-39$ years, 40-59 years, 60-79 years, and $\geq 80$ years), year of cancer diagnosis, and CCI score $(0,1-2,3+)$. We calculated proportions of histologically verified cancers and repeated all analyses restricted to those (Sub-analysis 1). In another sub-analysis, we categorized the combination T1NxMx as a complete TNM registration (Sub-analysis 2).

Analyses were performed using $\mathrm{SAS}^{\circledR}$ (v 9.2; SAS Inc, Cary, NC).

\section{Results}

We identified 5178 patients with incident invasive bladder cancer during the study period (2004-2009). Seventy-two percent were men $(n=3744)$ and $28 \%$ were women $(n=1434)$. Median age at diagnosis was 72.9 years, without any major gender difference.

Overall completeness of the TNM stage was $44.1 \%$ (95\% CI: 42.7-45.5) and this was similar among men and women: 44.3\% (95\% CI: 42.7-45.9) and 43.5\% (95\% CI: 41.0-46.1), respectively (Table 1). Overall completeness changed marginally when restricting the analysis to histologically verified cancers $(44.9 \% ; n=4892$ verified cases).

Stage completeness declined with increasing age (Table 1). Only 25.5\% (95\% CI: 23.2-27.9) of patients aged 80 years and older had a complete registration. This was mainly due to missing assessment of lymph node $(\mathrm{N}$-completeness $=29.1 \%)$ or distant metastases $(\mathrm{M}$-completeness $=35.2 \%)$. Stage completeness also declined with increasing level of CCI. Overall completeness of TNM-stage was 48.4\% (95\% CI: 46.6-50.3) among patients with the lowest CCI score, compared with $34.0 \%$ (95\% CI: 30.4-37.8) among those with the highest score. Completeness was lowest for presence of lymph node metastasis $(\mathrm{N})$, although with some improvement over time, from $45.7 \%$ in 2004 to $50.5 \%$ in 2009 . Similar tendencies were observed for metastasis (M) and TNM overall, whereas completeness of the $\mathrm{T}$ stage declined slightly, from $92.5 \%$ in 2004 to $89.8 \%$ in 2009 .

When classifying the combination T1NxMx as a complete stage registration, overall completeness of TNM stage increased to $61.8 \%$ (919 patients changed status from having incomplete to complete registration).

Using the algorithm for localized, regional, and distant disease (Appendix), the proportion of tumors with unknown stage declined to $29.6 \%$ (Table 2). Again, patients of older age or with a high level on the CCI had the highest proportion of tumors of unknown stage.

\section{Discussion}

In this study on TNM stage completeness for invasive bladder cancer in the DCR, we found that the overall completeness was less than $50 \%$. The proportion of cancer patients with unknown stage increased with increasing age and level

Table I Completeness of tumor, node, and metastasis (TNM) registration among bladder cancer patients in the Danish Cancer Registry

\begin{tabular}{|c|c|c|c|c|c|c|c|c|}
\hline & \multicolumn{2}{|c|}{ TNM-completeness } & \multicolumn{2}{|c|}{ T-completeness } & \multicolumn{2}{|c|}{ N-completeness } & \multicolumn{2}{|c|}{ M-completeness } \\
\hline & $\%(n)$ & $95 \% \mathrm{Cl}$ & $\%(n)$ & $95 \% \mathrm{Cl}$ & $\%(n)$ & $95 \% \mathrm{Cl}$ & $\%(\mathbf{n})$ & $95 \% \mathrm{Cl}$ \\
\hline \multicolumn{9}{|c|}{ Year of diagnosis } \\
\hline 2004 & 43.1 (387) & $39.9-46.4$ & $92.5(831)$ & $90.7-94.1$ & $45.7(410)$ & $42.4-48.9$ & $55.5(498)$ & $52.2-58.7$ \\
\hline 2005 & 41.3 (349) & $38.0-44.6$ & 91.3 (772) & $89.2-93.0$ & $44.6(377)$ & $41.2-47.9$ & $56.4(477)$ & $53.0-59.7$ \\
\hline 2006 & $4 I .4(357)$ & $38.2-44.7$ & $92.6(798)$ & $90.7-94.2$ & 45.I (389) & $41.8-48.5$ & $53.2(459)$ & $49.9-56.6$ \\
\hline 2007 & $46.1(38 I)$ & $42.7-49.5$ & $89.8(743)$ & $87.7-91.8$ & $49.8(4 \mid 2)$ & $46.4-53.2$ & $58.3(482)$ & $54.9-61.6$ \\
\hline 2008 & $47.5(396)$ & $44.2-50.9$ & 91.7 (764) & 89.7-93.4 & 51.1 (426) & $47.8-54.5$ & $58.7(489)$ & $55.3-62.0$ \\
\hline 2009 & $45.3(4 \mid 3)$ & $42.1-48.5$ & $89.8(819)$ & $87.7-91.6$ & $50.5(46 I)$ & $47.3-53.8$ & $56.5(5 \mid 5)$ & $53.2-59.7$ \\
\hline \multicolumn{9}{|l|}{ Sex } \\
\hline Female & $43.5(624)$ & $41.0-46.1$ & $89.7(1286)$ & 88.0-91.2 & $46.4(665)$ & $43.8-49.0$ & $56.3(808)$ & $53.8-58.9$ \\
\hline Male & 44.3 (1659) & $42.7-45.9$ & $91.9(344 I)$ & $91.0-92.8$ & $48.3(1810)$ & $46.8-50.0$ & $56.4(2 \mid 12)$ & $54.8-58.0$ \\
\hline \multicolumn{9}{|c|}{ Age group (years) } \\
\hline $0-39$ & $60.9(14)$ & $40.6-78.6$ & $78.3(18)$ & 58.7-91.2 & $60.9(14)$ & $40.6-78.6$ & $78.3(18)$ & $58.7-91.2$ \\
\hline $40-59$ & $56.8(353)$ & $52.8-60.6$ & $92.0(572)$ & 89.6-93.9 & $60.6(377)$ & $56.7-64.4$ & $72.0(448)$ & $68.4-75.5$ \\
\hline $60-79$ & 48.9 (1588) & $47.2-50.6$ & $93.0(3019)$ & $92.1-93.8$ & $52.7(1710)$ & $50.9-54.4$ & $61.6(2001)$ & $59.9-63.3$ \\
\hline$\geq 80$ & $25.5(328)$ & $23.2-27.9$ & $86.9(1118)$ & $85.0-88.7$ & 29.1 (374) & $26.7-31.6$ & $35.2(453)$ & $32.7-37.9$ \\
\hline \multicolumn{9}{|c|}{ Comorbidity } \\
\hline Low & 48.4 (1384) & $46.6-50.3$ & $92.9(2654)$ & $91.9-93.8$ & $51.7(1477)$ & $49.9-53.5$ & 60.5 (I728) & $58.7-62.2$ \\
\hline Medium & $40.5(687)$ & $38.2-42.8$ & $90.6(1537)$ & $89.1-91.9$ & $44.8(760)$ & $42.4-47.2$ & 52.7 (895) & $50.4-55.1$ \\
\hline High & $34.0(2 \mid 2)$ & $30.4-37.8$ & $86.0(536)$ & $83.2-88.6$ & $38.2(238)$ & $34.5-42.1$ & 47.7 (297) & $43.8-51.6$ \\
\hline
\end{tabular}

Abbreviation: $\mathrm{Cl}$, confidence interval. 
Table 2 Staging of bladder cancer patients in the Danish Cancer Registry

\begin{tabular}{|c|c|c|c|c|c|}
\hline & $\begin{array}{l}\text { Localized } \\
\text { n (\%) }\end{array}$ & $\begin{array}{l}\text { Regional } \\
\text { n (\%) }\end{array}$ & $\begin{array}{l}\text { Distant } \\
\text { n (\%) }\end{array}$ & $\begin{array}{l}\text { Unknown } \\
\text { n (\%) }\end{array}$ & $\begin{array}{l}\text { Total } \\
\mathrm{n}\end{array}$ \\
\hline \multicolumn{6}{|c|}{ Year of diagnosis } \\
\hline 2004 & $5 \mid 4(57.2)$ & $42(4.7)$ & $72(8.0)$ & $270(30.1)$ & 898 \\
\hline 2005 & $453(53.5)$ & $37(4.4)$ & $88(10.4)$ & $268(31.7)$ & 846 \\
\hline 2006 & $455(52.8)$ & $61(7.1)$ & $75(8.7)$ & $27 \mid(3 I .4)$ & 862 \\
\hline 2007 & $463(56.0)$ & $43(5.2)$ & $92(11.1)$ & $229(27.7)$ & 827 \\
\hline 2008 & $483(58.0)$ & $39(4.7)$ & $82(9.8)$ & $229(27.5)$ & 833 \\
\hline 2009 & $536(58.8)$ & $31(3.4)$ & $79(8.7)$ & $266(29.2)$ & 912 \\
\hline \multicolumn{6}{|l|}{ Sex } \\
\hline Female & $687(47.9)$ & $72(5.0)$ & $167(11.6)$ & $508(35.4)$ & 1434 \\
\hline Male & $2217(59.2)$ & $18 \mid(4.8)$ & $321(8.6)$ & $1025(27.4)$ & 3744 \\
\hline \multicolumn{6}{|c|}{ Age group (years) } \\
\hline $0-39$ & $10(43.5)$ & $2(8.7)$ & $4(17.4)$ & $7(30.4)$ & 23 \\
\hline $40-59$ & $362(58.2)$ & $51(8.2)$ & $88(14.1)$ & $121(19.5)$ & 622 \\
\hline $60-79$ & $1959(60.3)$ & $184(5.7)$ & $310(9.5)$ & $794(24.5)$ & 3247 \\
\hline$\geq 80$ & $573(44.6)$ & $16(1.2)$ & $86(6.7)$ & $611(47.5)$ & 1286 \\
\hline \multicolumn{6}{|c|}{ Comorbidity } \\
\hline Low & $1683(58.9)$ & $174(6.1)$ & $268(9.4)$ & $733(25.6)$ & 2858 \\
\hline Medium & $913(53.8)$ & $66(3.9)$ & $159(9.4)$ & $559(32.9)$ & 1697 \\
\hline High & $308(49.4)$ & $13(2.1)$ & $61(9.8)$ & $24 I(38.7)$ & 623 \\
\hline Total & $2904(56.1)$ & $253(4.9)$ & $488(9.4)$ & I 533 (29.6) & 5178 \\
\hline
\end{tabular}

of comorbidity. This resulted mainly from inadequate assessment of lymph node or distant metastases.

In line with our findings, Lau et al found that stage was missing for $63 \%$ of all cancers in the American Electronic Medical Records. ${ }^{14}$ However, in the US Surveillance, Epidemiology, and End Results (SEER) program, the percentage of unknown stage was only $3 \%$ for bladder cancer during the period 2001-2007. ${ }^{15}$ In that survey, median age at cancer diagnosis was 78 years, and the distribution of cases between men and women was similar to those in our study. There was no information on the comorbidity level. However, it is unlikely that differences in comorbidity level between Danish patients and patients included in the SEER database could explain the markedly better stage registration among the US patients. Notably, staging in the US survey was performed on the basis of the SEER Summary Stage 2000 (based on pathologic, operative, and clinical information) and not the TNM classification. ${ }^{16}$ Registries supplying information to the SEER database are rewarded when performing well in reliability studies. This might be a reason for the higher level of completeness of stage registration in the SEER database than in the DCR. ${ }^{17}$ In agreement with our results, several studies on quality of data in cancer registries have found that the percentage of cancer cases with unknown stage increased substantially with increasing age and level of comorbidity. ${ }^{18-22}$ We found a higher proportion of cancer of unknown stage among women than among men. Also, distant metastases were more frequent among women (Table 2). These are both interesting findings, considering that survival following bladder cancer has been reported to be poorer in women compared with men. ${ }^{23}$

We may only speculate on the reasons for the incompleteness in registration of invasive bladder cancer. We found that a large proportion of bladder cancer patients were registered with T1NxMx. A T1 tumor has grown from the layer of cells lining the bladder (mucosa) into the underlying connective tissue (lamina propria), but does not invade the muscle (detrusor) layer of the bladder. T1 tumors invading deeply into the lamina propria have been shown to have a high potential for progressing into $\mathrm{T} 2$ tumors, thus affecting the prognosis. ${ }^{24,25}$ However, it is generally clinically accepted that $\mathrm{T} 1$ tumors only seldom disseminate. Consequently, most patients with a T1 tumor do not undergo examination for regional or distant metastases. Such cases will be registered with the codes Nx and Mx (as N0 and M0 statuses have not been verified). In that context, a registration of T1NxMx more likely reflects actual clinical practice, rather than incomplete coding. Classification of T1NxMx as a complete registration may thus give a more meaningful estimate on the completeness of stage registration in the DCR.

Bladder cancer is mainly seen in elderly patients. ${ }^{23}$ As older age and a higher level of comorbidities are often related, it is conceivable that a substantial proportion of bladder cancer patients are too fragile to endure massive surgery or adjuvant chemotherapy, which is the recommended treatment for advanced or metastatic cancer. The combination of old age and high comorbidity may restrain medical doctors from undertaking further examinations of lymph node and distant metastases status, as complete staging would not affect the treatment choice and would be considered futile from a clinical perspective. Patient choice could have contributed to low TNM completeness, as elderly patients are more likely to refrain from further examinations and exhausting treatment.

In epidemiological research, there are often serious concerns as to how to handle missing data correctly. Our findings indicate that restricting analyses to patients with complete data may yield substantially selected study populations, as missing data are more common among elderly and/or comorbid patients. The presence of lymph node metastasis has been shown to be the most important prognostic factor for bladder cancer mortality. ${ }^{26-28}$ From a clinical point of view, many patients with lymph node metastases will also have distant 
"micro-metastases," and are therefore treated as such. Our results indicate an association between missing data on $\mathrm{N}$ stage and high age and/or comorbidity score. This could lead to bias, eg, in prognosis studies. Presence of distant metastasis is also associated with increased mortality and the same arguments thus apply for missing data on M stage. ${ }^{29,30}$ We showed that a clinically based algorithm for tumor stage, allowing for some degree of missing data, could reduce the proportion of tumors of unknown stage markedly. We believe that this algorithm is applicable in both etiologic and prognostic studies of bladder cancer. In such studies, it would be advisable to analyze bladder cancer cases of unknown stage as a separate category. Alternatively, multiple imputation models, predicting values for missing data, may be considered.

Our study design allowed us only to examine the completeness of stage registration based on data in the cancer and hospital registries. In the current setting, we could not examine the accuracy of staging data, and thus evaluate potential errors in data entry, or misclassification. Such information would require medical chart review, or linkage to a valid clinical database, which were beyond the scope of this study. Another limitation of our study derives from the ICD-10 coding practice for bladder cancer in Denmark. Patients presenting with a premalignant bladder tumor will receive an ICD-10 code accordingly. Despite later progression into invasive bladder cancer, no subsequent registration in the DCR will be performed. Hence, by including only incident cancers with ICD-10 code C67, we may miss patients who were initially registered with premalignant bladder tumors.

Stage is often crucial for the choice of treatment of specific cancer types. Therefore, missing data on cancer stage in the DCR may hamper the interpretation of observed differences in treatment and outcome in epidemiologic research. Thus, improvement in the registration of stage for bladder cancer is warranted. However, despite the limitations in the coding of TNM stage for bladder cancer, the DCR is an important resource for epidemiological studies of invasive bladder cancer.

\section{Disclosure}

The authors report no conflicts of interest in relation to this work.

\section{References}

1. Jemal A, Bray F, Center MM, Ferlay J, Ward E, Forman D. Global cancer statistics. CA Cancer J Clin. 2011;61(2):69-90.

2. Ferlay J, Shin HR, Bray F, Forman D, Mathers C, Parkin DM. Estimates of worldwide burden of cancer in 2008: GLOBOCAN 2008. Int J Cancer. 2010;127(12):2893-2917.
3. Danish Board of Health. Cancerregisteret 2009 [Cancer Registry 2009]. Copenhagen: Danish Board of Health; 2010. Danish. Available from: http://www.sst.dk/publ/Publ2010/DOKU/Registre/ Cancerregisteret2009.pdf. Accessed November 23, 2011.

4. Greene F, Page D, Fleming I, et al. AJCC Cancer Staging Manual, 6th ed. New York: Springer-Verlag; 2002.

5. Youssef RF, Lotan Y. Predictors of outcome of non-muscle-invasive and muscle-invasive bladder cancer. Scientific World Journal. 2011;11: 369-381.

6. Danish Board of Health. Kræftplan II [Cancer Plan II; web page on the Internet]. Copenhagen: Danish Board of Health; nd. Available at: http://www. sst.dk/Planlaegning $\% 20$ og $\% 20 \mathrm{kvalitet} /$ Kraeftbehandling/Nationale $\% 20$ planer/Kraeftplan_II.aspx. Accessed November 28, 2011. Danish.

7. Gjerstorff ML. The Danish Cancer Registry. Scand J Public Health. 2011;39(Suppl 7):42-45.

8. Pedersen CB. The Danish Civil Registration System. Scand J Public Health. 2011;39(Supp1 7):22-25.

9. Storm HH, Michelsen EV, Clemmensen IH, Pihl J. The Danish Cancer Registry - history, content, quality and use. Dan Med Bull. 1997;44(5):535-539.

10. Danish Board of Health. Det moderniserede Cancerregister-metode og $k v a l i t e t$ [The Modernized Cancer Registry - Methodology and Quality]. Copenhagen: Danish Board of Health; 2009. Danish. Available at: http:// www.sst.dk/ /media/Indberetning\%20og\%20statistik/Cancerregisteret/ Metodebeskrivelse_publikation\%20Cancerregisteret.ashx. Accessed April 25, 2012.

11. Lynge E, Sandegaard JL, Rebolj M. The Danish National Patient Register. Scand J Public Health. 2011;39(Suppl 7):30-33.

12. Charlson ME, Pompei P, Ales KL, MacKenzie CR. A new method of classifying prognostic comorbidity in longitudinal studies: development and validation. J Chronic Dis. 1987;40(5):373-383.

13. Thygesen SK, Christiansen CF, Christensen S, Lash TL, Sorensen HT. The predictive value of ICD-10 diagnostic coding used to assess Charlson comorbidity index conditions in the population-based Danish National Registry of Patients. BMC Med Res Methodol. 2011;11:83.

14. Lau EC, Mowat FS, Kelsh MA, et al. Use of electronic medical records (EMR) for oncology outcomes research: assessing the comparability of EMR information to patient registry and health claims data. Clin Epidemiol. 2011;3:259-272.

15. US National Cancer Institute. SEER Stat Fact Sheets: Bladder. Bethesda, MD: US National Cancer Institute; 2012. Available from: http://seer. cancer.gov/statfacts/html/urinb.html. Accessed January 6, 2012.

16. US National Cancer Institute. SEER registries [database on the Internet]. Bethesda, MD: US National Cancer Institute; nd. Available from: http:// seer.cancer.gov/about/. Accessed January 6, 2012.

17. Yu JB, Gross CP, Wilson LD, Smith BD. NCI SEER public-use data: applications and limitations in oncology research. Oncology (Williston Park). 2009;23(3):288-295.

18. Merrill RM, Sloan A, Anderson AE, Ryker K. Unstaged cancer in the United States: a population-based study. BMC Cancer. 2011;11:402.

19. Koroukian SM, Xu F, Beaird H, Diaz M, Murray P, Rose JH. Complexity of care needs and unstaged cancer in elders: a populationbased study. Cancer Detect Prev. 2007;31(3):199-206.

20. Yancik R, Wesley MN, Ries LA, Havlik RJ, Edwards BK, Yates JW. Effect of age and comorbidity in postmenopausal breast cancer patients aged 55 years and older. JAMA. 2001;285(7):885-892.

21. Havlik RJ, Yancik R, Long S, Ries L, Edwards B. The National Institute on Aging and the National Cancer Institute SEER collaborative study on comorbidity and early diagnosis of cancer in the elderly. Cancer. 1994;74(Suppl 7):2101-2106.

22. Klassen AC, Curriero F, Kulldorff M, Alberg AJ, Platz EA, Neloms ST. Missing stage and grade in Maryland prostate cancer surveillance data, 1992-1997. Am J Prev Med. 2006;30(Suppl 2):S77-S87.

23. Lund L, Erichsen R, Norgaard M, Larsen EH, Borre M, Jacobsen J. Survival of invasive bladder cancer patients, 1998-2009; a central and northern Denmark population-based cohort study. Clin Epidemiol. 2011;3(Suppl 1):47-51. 
24. Hermann GG, Horn T, Steven K. The influence of the level of lamina propria invasion and the prevalence of p53 nuclear accumulation on survival in stage T1 transitional cell bladder cancer. $J$ Urol. 1998;159(1):91-94.

25. Younes M, Sussman J, True LD. The usefulness of the level of the muscularis mucosae in the staging of invasive transitional cell carcinoma of the urinary bladder. Cancer. 1990;66(3):543-548.

26. Bassi P, Ferrante GD, Piazza N, et al. Prognostic factors of outcome after radical cystectomy for bladder cancer: a retrospective study of a homogeneous patient cohort. J Urol. 1999;161(5):1494-1497.

27. Bella AJ, Stitt LW, Chin JL, Izawa JI. The prognostic significance of metastatic perivesical lymph nodes identified in radical cystectomy specimens for transitional cell carcinoma of the bladder. $J$ Urol. 2003;170(6 Pt 1):2253-2257.
28. Shariat SF, Karakiewicz PI, Palapattu GS, et al. Outcomes of radical cystectomy for transitional cell carcinoma of the bladder: a contemporary series from the Bladder Cancer Research Consortium. J Urol. 2006;176(6 Pt 1):2414-2422; Discussion 2422.

29. Sternberg CN, Yagoda A, Scher HI, et al. Methotrexate, vinblastine, doxorubicin, and cisplatin for advanced transitional cell carcinoma of the urothelium. Efficacy and patterns of response and relapse. Cancer. 1989;64(12):2448-2458.

30. Türkölmez K, Tokgöz H, Reşorlu B, Köse K, Bedük Y. Muscle-invasive bladder cancer: predictive factors and prognostic difference between primary and progressive tumors. Urology. 2007;70(3):477-481. 


\section{Appendix}

Appendix Algorithm for bladder cancer staging according to TNM classification in the Danish Cancer Registry

\begin{tabular}{|c|c|}
\hline Stage & TNM codes \\
\hline \multirow[t]{3}{*}{ Localized } & Ta, is, I-4, x NO MO \\
\hline & $\mathrm{Ta}$, is, I-2 No Mx \\
\hline & $\mathrm{Ta}$, is, I Nx M0, Mx \\
\hline Regional & $\mathrm{Ta}$, is, I-4, $\times \mathrm{NI}-3 \mathrm{MO}$ \\
\hline \multirow[t]{3}{*}{ Distant } & $\mathrm{Ta}$, is, I-4, $\times \mathrm{NI}-3 \mathrm{MI}$ \\
\hline & $\mathrm{Ta}$, is, I-4, x NO MI \\
\hline & $\mathrm{Ta}$, is, I-4, $\times \mathrm{N} \times \mathrm{MI}$ \\
\hline \multirow[t]{4}{*}{ Unknown } & $\mathrm{T} 2-4, \mathrm{~N} \times \mathrm{M} 0, \mathrm{x}$ \\
\hline & T3-4, x N0 Mx \\
\hline & TI-4, x NI-3 Mx \\
\hline & TO N0-3, x M0, I, x \\
\hline
\end{tabular}

Notes: Ta and Tis apply to noninvasive bladder cancers, however, they are included in the algorithm, due to the possibility of misclassification. T0 denotes cancer of unknown primary localization, only included in the unknown category, again due to possible misclassification. In our material, only four patients were registered with a TO code.

Abbreviation: TNM, tumor, node, and metastasis.

\section{Publish your work in this journal}

Clinical Epidemiology is an international, peer-reviewed, open access journal focusing on disease and drug epidemiology, identification of risk factors and screening procedures to develop optimal preventative initiatives and programs. Specific topics include: diagnosis, prognosis, treatment, screening, prevention, risk factor modification, systematic

Submit your manuscript here: http://www.dovepress.com/clinical-epidemiology-journal
Dovepress

reviews, risk \& safety of medical interventions, epidemiology \& biostatical methods, evaluation of guidelines, translational medicine, health policies \& economic evaluations. The manuscript management system is completely online and includes a very quick and fair peer-review system, which is all easy to use. 